\title{
Saúde Coletiva: Revisitando a sua História e os Cursos de Pós-Graduação
}

\author{
Everardo Duarte Nunes ${ }^{1}$
}

\begin{abstract}
Resumo: Neste trabalho, o autor analisa os principais aspectos da história da Saúde Coletiva e dos cursos de pós-graduação em Saúde Coletiva no Brasil, restritos ao Mestrado e Doutorado. A partir dos primeiros cursos, iniciados nos anos 70, verifica-se a sua paulatina ampliação até os dias atuais. No momento, existem no país 24 cursos, incluindo os denominados genericamente de Saúde Coletiva ou Saúde Pública, e os que se especializaram em Epidemiologia. Estão excluídos desta relação os cursos da área da enfermagem, odontologia social, administração em saúde e saúde da criança. São levantados alguns aspectos referentes aos fatores que foram importantes na emergência desses cursos, e que são tanto de ordem políticosocial, sanitários, como institucionais; a origem da denominação Saúde Coletiva; as discussões sobre o conceito de coletivo; os principais conteúdos que configuram a área. Nas Considerações Finais, ressalta-se o fato bastante atual da especializaçâo na área da Saúde Coletiva, com a formação de áreas de concentraçào, das quais o destaque é a Epidemiologia; faz-se também referência às disciplinas consideradas como núcleo comum à área, destacando o papel das Ciências Sociais.
\end{abstract}

Palavras-Chave: Saúde Coletiva, história; Saúde Coletiva, ensino; Saúde Coletiva, mestrado e doutorado; Saúde Coletiva, Brasil.

Summary: The paper analyzes the milestones of the history of Public Health and of the Post-graduation stricto sensu courses in Brazil. Since its beginnings in the 70 s we can observe a gradual broadening of the scope and an increase of the number of available Post-graduation courses. Presently, there are 24 Public Health Post-graduation courses in Brazil, including both the ones with a comprehensive curriculum and the ones mainly concerned with Epidemiology. The present analysis does not include courses in the field of nursing, social odontology, health administration and social pediatrics. The main aspects involved in the creation of those courses were studied in detail, including social and political background, data concerning public health context prevailing in Brazil and institutional issues. The paper also addresses the terminology employed in the field, e.g. Public Health, Community Medicine... as concepts embodying its guidelines. Finally, the growing specialization in the realm of Public Health was discussed, exemplifying it with the contemporary development of Epidemiology. In order to preserve a "core" of knowledges common to the different specialties, the paper highlights the role of Social Sciences applied to health.

Keywords: Public Health, history; Public Health, teaching; Master and Doctor in Public Health Courses; Public Health in Brazil.

\footnotetext{
' Departamento de Medicina Preventiva e Social - Faculdade de Ciências Médicas, Unicamp, Campinas, São Paulo.
} 


\section{Introdução}

Um fato que tem sido constantemente apontado no plano educacional brasileiro é a bem sucedida experiência dos cursos de pósgraduação. Não se trata, neste momento, de reavaliar esta situação em seu conjunto, mas rever como no campo da Saúde Coletiva esta proposta vem se desenvolvendo. Embora não seja objeto deste trabalho analisar as estreitas relações entre desenvolvimento social e formação profissional, não se pode deixar de apontar que no nível da formação na pósgraduação a capacitação de pesquisadores $e$ a profissionalização docente são elementos fundamentais para alavancar a ciência e a tecnologia. Nesse sentido, este trabalho procura recuperar de forma geral a trajetória da Saúde Coletiva como campo de práticas e saberes, assim como a história do desenvolvimento dos cursos de mestrado e doutorado, em crescente expansão, que nessa área têm contribuído substancialmente para a criação de uma "comunidade científica" que na academia, nos serviços e na gestão técnicoadminstrativa já demonstrou capacidade para ir além do projeto e firmar-se como realidade.

Trabalhos anteriores (ABRASCO, 1982; ABRASCO, 1983; ABRASCO, 1986, ABRASCO, 1988) servem de base documental para muitos dos aspectos tratados neste texto, que busca sistematizar informações e idéias centrais, com base também em autores que ao longo de quase duas décadas têm estudado os fundamentos conceituais da medicina preventiva e social, da saúde pública e da saúde coletiva.

\section{As Origens de um Pensamento Social em Saúde}

Mesmo sem a pretensão de estabelecer uma revisão histórica detalhada sobre as origens mais longínquas de um pensamento social em relação à saúde, não se pode dei- xar de mencionar que as suas bases inscrevem-se nos movimentos europeus de reforma sanitária e de reforma médica ocorridos na segunda metade do século XIX. Esses movimentos trazem, juntamente com as idéias liberais, a consciência da importância do papel dos fatores sociais para a compreensão dos problemas de saúde e das relaçôes da medicina com os assuntos públicos, e, em certo sentido, como no caso da França, o do monopólio da profissão médica sobre o saber e a prática da Medicina. Data desse momento a definição da ciência médica como uma ciência social. Até então, as denominações que acompanhavam essas idéias eram muito variadas: higiene social, polícia médica, saúde pública, medicina legal. Foi durante o movimento de reforma médica, ocorrido nesse momento, que se procurou agrupar sob a rubrica de medicina social um conjunto de preocupações em torno de algo com maior consistência e organização. Refiro-me à idéia desenvolvida por Jules Guérin, quando afirmava, em março de 1848: "Tínhamos tido já ocasião de indicar as numerosas relações que existem entre a medicina e os assuntos públicos. Apesar destas abordagens parciais e não coordenadas que havíamos tentado incluir sob rubricas tais como polícia médica, saúde pública e medicina legal, com o tempo estas partes separadas vieram a se juntar em um todo organizado e atingir seu mais alto potencial sob a designação de medicina social, que melhor expressa seus propósitos...".

De outro lado, são bastante conhecidos os estudos que mostram que a intervenção sobre a saúde da coletividade iria se expressar diferentemente, conforme as formações sócio-econômicas. De forma paradigmática, Foucault (1979) analisa estas formas de intervenção quando mostra a origem de uma chamada "medicina urbana", na França, "medicina estatal", na Alemanha e "medicina da força de trabalho", na Inglaterra. Em verdade, a partir da segunda metade do século XIX, afloram nesses países tentativas de compre- 
ender os fenômenos patológicos dentro de quadros explicativos mais abrangentes. São sobejamente conhecidas as idéias de Neumann e Virchow, quando afirmavam: "A ciência médica é intrínseca e essencialmente uma ciência social e, até que isto não seja reconhecido na prática, não seremos capazes de desfrutar seus benefícios e teremos que nos contentar com um vazio e uma mistificação" e "A medicina é uma ciência social e a política nada mais é do que medicina em uma grande escala" (Rosen, 1983). Em outros contextos, as análises são extremamente coerentes quando demonstram como os fatores econômicos, políticos e icleológicos estão presentes na configuração das propostas no campo da saúde. Estudo recente, por mim realizado, sobre a história da saúde pública, que revisa trabalhos escritos a partir da década de 70 , não deixa dúvidas quanto ao papel dos contextos sócio-políticos na emergência das práticas sanitárias (Nunes, 1994). Voltando à questão apontada por Guérin (1848), verifica-se que esse esforço de nominar um campo disperso de atividades não seria adotado de forma unânime. Tanto assim, que uma nomenclatura diversa persistiria e estaria presente ao longo do tempo e seríamos herdeiros dessa tradição. No Brasil, as faculdades denominaram-se de higiene e saúde pública, assim como as primeiras cátedras e departamentos que se estabeleceram junto às faculdades de medicina neste século. E, ainda hoje, convivemos com as expressões medicina social, saúde pública e saúde coletiva; não que essas expressões não sejam portadoras de significados específicos, como já formulado por Franco \& Nunes (1991) quando assinalam que: "Particularmente no Brasil, e de forma crescente em outros países da Região, vem se utilizando - termo Saúde Coletiva. Este tenta superar a medicalização e o contraste público-privado, ressaltando a temática da saúde e seu caráter coletivo. Não sendo redutível o social ao coletivo, tampouco esta expressão tem podido resolver totalmente a insuficiência das denomina- ções em questão". Observa-se, inclusive, um recrudescimento da expressão Saúde Pública, obviamente, sem os reducionismos que a caracterizaram no passado (OPAS, 1992). Mas, como diz Schramm (1993), em seu recente doutoramento: "intuitivamente, as três expressões referem-se a uma mesma realidade de 'reunião' (coletivo), de 'associação' (social), de 'coisa comum' (público)".

De um modo geral, pode-se dizer que o segundo momento onde se detecta de forma mais sistemática a incorporação de uma aborclagem do social em saúde será a partir do término da $2^{a}$ Guerra Mundial. Muitas são as mudanças que acontecem em todos os países, afetando não somente a sociedade como um todo, mas provocando alteraçōes em diversos níveis, como o educacional e o da saúde. Este debate, que se inicia nos Estados Uniclos, atinge a América Latina quase vinte anos depois. Há casos esporádicos de ensino das ciências sociais em escolas brasileiras, como os cursos de Problemas de Sociologia Aplicada à Higiene, na Faculdade de Saúde Pública/USP, em 1946, e o de "Fundamentos Sócio-econômicos", na Escola Nacional de Saúde Pública, do Rio de Janeiro; mas foi na segunda metade dos anos 50 que se instalou um grande debate em torno das reformas do ensino na saúde, particularmente em relação à formação médica. Desencadeado na Europa e Estados Unidos, este clebate teria importantes repercussōes na América Latina. Dentre os inúmeros seminários sobressaem os que se realizaram em 1955 e 1956, em Viña del Mar (Chile) e Tehuacán (México), que definiram para a América Latina as propostas da medicina preventiva, daí decorrendo uma revalorização do social. A proposta era não somente preencher o vazio deixado pela $\mathrm{Hi}$ giene, mas definir o papel clo médico perante a família e a comunidade e criar uma nova atitude preventivista que deveria ser desenvolvida durante o processo de formação médica. No fundo da questão estava a pretensão de reordenar a prática médica, formando pro- 
fissionais portadores de um novo perfil. Nos currículos com conteúdos inovadores destacavam-se as dimensões integral, preventiva e social (Arouca, 1975).

Sem dúvida, a grande conquista desse período foi a implantação dos departamentos de medicina preventiva e social, que veio acompanhada pela instalação de algumas disciplinas e temas como a epidemiologia, as ciências sociais (à época, denominadas ciências da conduta), o planejamento, a organização e administração de serviços de saúde, a medicina quantitativa (através da bioestatística). Além desses aspectos de estruturação curricular - com inovaçôes, de fato, importantes -, não se pode minimizar a influência destas propostas ao pensar de forma crítica a educação, a organização e a prática médica. As críticas ao modelo que fundamentou o ensino da medicina preventiva e social seria tarefa dos anos 70, e, passadas duas décadas, nem todas as questões então apontadas foram resolvidas; por exemplo: a integração disciplinar, as relações teoria/prática, a integração do ensino à rede de serviços, etc.

É importante lembrar, para que este esboço histórico não fique sobremodo incompleto em relação ao campo específico do ensino da saúde pública, as suas vinculações com o ensino médico. Assim, o Departamento de Higiene foi criado junto à Faculdade de Medicina e Cirurgia de São Paulo, em 1918, através de um acordo entre o Governo de São Paulo e a Fundação Rockefeller. Em 1924, foi oficializado o Instituto de Higiene que, com isso, deixa de funcionar como seção da Faculdade de Medicina e Cirurgia; em 1931, ocorreu o reconhecimento oficial do Instituto de Higiene e Saúde Pública, incorporado à Universidade de São Paulo, em 1938. Em 1945 ele é transformado em Faculdade, adotando a denominação de Faculdade de Saúde Pública, em 1969 (Candeias, 1984). Portanto, menos de uma década depois da criação da primeira instituição desse tipo no mundo, o Brasil iniciava a formação de recursos humanos na área da saúde pública. Como tem sido observado por muitos estudiosos (existindo igualmente neste relato esta perspectiva), as questões da saúde pública não permaneceram adstritas somente às faculdades de saúde pública, mas se deslocaram para departamentos e outras instituições congêneres. Não sendo nosso objeto estabelecer a trajetória desses cursos, mas de assinalar seus pontos de inflexão numa história mais ampla, permitome voltar aos anos 70 .

Nos anos 70, os movimentos de reforma médica iriam incorporar novas dimensões; destas, a principal ficou conhecida como medicina comunitária ou saúde comunitária. Esta questão, posteriormente, seria alvo de intensas críticas. Estas voltaram-se para o caráter controlador, manipulador e ordenador presentes nos chamados programas de "Organização e Desenvolvimento de Comunidades", e também em decorrência de suas limitações como estratégia de ensino. A legitimação de uma disciplina para as novas faculdades de medicina seria decorrência da adoção do Currículo Mínimo, aprovado em 1969, com a criação de uma disciplina intitulada "Estudos da Saúde Coletiva". De certa forma, mesmo com as limitações impostas pelos clássicos currículos de ensino médico, percebia-se a tentativa de introduzir um conhecimento de uma natureza até então estranha ao plano de estudos - com isso, legaliza-se a presença do social. Este esforço estendeu-se pela década de 60. Isto não quer dizer que até esse momento nada houvesse sido produzido. Interessante verificar que a questão dos "fatores sócio-culturais na saúde” já era pesquisada por antropólogos que trabalhavam junto a serviços de saúde no final dos anos $30 \mathrm{e}$ durante a década de 40. É o caso de Charles Wagley, que se encontrava no Brasil, desde 1939, a convite do Museu Nacional, realizando estudos na Região Amazônica para a instalação do Serviço Especial de Saúde Pública, onde permaneceu até 1946, tendo assumido a direção da Divisão de Educação Sanitária. Na 
década de 50, outro antropólogo, Kalervo Oberg, realiza, a pedido do SESP (Serviço Especial de Saúde Pública) e do Instituto de Assuntos Interamericanos, estudos de comunidades (no Pará, Espírito Santo e Paraná), a fim de subsidiar o planejamento sanitário.

Também no início dos anos 70, assiste-se ao início das discussões acerca da extensão de cobertura e da racionalização dos usos de recursos para a saúde. Esta discussão, que teve lugar em 1972, na III Reunião Especial de Ministros de Saúde das Américas, propunha ainda a intervenção do Estado, a fim de garantir a saúde como um direito inalienável de todos os indivíduos. Lembre-se que, neste momento, cerca de $37 \%$ da população não recebia qualquer forma de atenção à saúde.

Assim, na década de 70, enfatizou-se a atenção primária e seus desenvolvimentos paralelos, salientou-se a integração docenteassistencial, observando-se ainda uma intensa procura da redefinição das ações de saúde, que têm nas práticas coletivas o seu principal ponto de referência. Acrescente-se que, em 1975, em nível do Ministério da Saúde, e em 1976, em nível da Secretaria de Estado da Saúde de São Paulo, ocorreram importantes modificações na organização da saúde públi$\mathrm{ca}$ e intensos movimentos de sanitaristas. Entre as propostas então formuladas temos o PIASS (Programa de Interiorização das Ações de Saúde e Saneamento do Nordeste), em agosto de 1976, e, em agosto de 1980, o PREV-SAÚDE (Programa Nacional de Serviços Básicos de Saúde), que não chegou a ser concretizado.

Sem dúvida, quando se analisam retrospectivamente as áreas da Medicina Preventiva e Social e a Saúde Pública, verifica-se que a década de 70 sobressai em todos os pontos. Percebe-se, claramente, que havia muitos motivos para que as atenções se voltassem para a saúde. De um lado, as questões de saúde e de atenção médica não haviam sido equacionadas e, por sinal, haviam se deteriorado de outro, não mais se podia contar como exclusivos os modelos teóricos que até então haviam predominado no sentido de explicar essa realidade. Dizia-se que havia uma crise tanto na geração de conhecimentos, como de uma determinada prática. Apesar dos milagres econômicos latino-americanos, presenciava-se uma crescente deterioração da saúde coletiva. Ao lado de um aumento na mortalidade infantil, que já havia apresentado sinais anteriores de decréscimo, a desnutrição era um problema não resolvido e outros começavam a se manifestar, como os acidentes de trabalho e o aumento das doenças cardiovasculares.

Interessante que, ao final da década, quando é criada a Associação de Pós-Graduação em Saúde Coletiva, com o objetivo de rearticular a formação de pessoal na área, a proposta assentava-se, justamente, na identificação dos graves problemas que os anos 70 não haviam sido resolvidos e que haviam, mesmo, se agravado durante esse período. Assim, os princípios básicos da Associação destacavam que as diferenças nos padrões de morbi-mortalidade traduziam a heterogeneidade estrutural, refletindo os desequilíbrios sociais causados pelo processo global de desenvolvimento. Ao caracterizar o sistema de prestação de serviços como profundamente marcado pela desigualdade de acesso, chamava-se a atenção para a questão do "empresariamento" da saúde, no que ficou conhecido como a "indústria da saúde" (ABRASCO, 1982).

Percebia-se que as questões de saúde não poderiam continuar a ser discutidas sem um profundo repensar que envolvesse a formação de recursos humanos dentro de "novas" categorias. Não bastava a denúncia. Precisava-se de um arsenal teórico que desse conta de uma situação onde estavam presentes contradições e conflitos. Nesse sentido, assistese a um movimento que, proveniente do final dos anos 60, encontra um solo fértil para realizar as suas propostas e passa a contar com o apoio da Organização Panamericana da Saúde. Refiro-me aos seminários sobre o 
ensino e a metodologia das ciências sociais em saúcle, realizados em Ribeirào Preto \& Campinas, Buenos Aires e Cuenca (Equador), assim como à publicação, em 1972, do livro Edacación Médica en la América Latina, de autoria de Juan César García, que seria, a partir clesse momento, marco de referência nos estudos sobre educação médica, aí incluida a mais completa avaliaçào sobre o ensino da medicina preventiva e social até então elaborada.

Gostaria de me deter um pouco mais neste momento da história, de modo a situar quais eram as questões teóricas mais candentes. Em 1972, por ocasião de um importante seminário para avaliar a questão das ciências sociais em saúde, realizado em Cuenca, sob o patrocínio da OPAS, procede-se a um vigoroso questionamento das abordagens teóricas utilizadas. Põe-se em discussão a sociologia médica funcionalista, explicitando-se suas limitações explicativas, desvios ideológicos e parcelamento da realidade estudada. Criticavá-se, então, a concepção estática na análise dos problemas de saúde, a descrição formalista da relação entre tais problemas e outras esferas dos processos produtivos em geral. Enfim, buscava-se entender a determinação estrutural da produção e distribuiçào da doença e das relações entre a organização das açôes de saúde e as formações sócio-econômicas. Ressaltava-se ainda a importância das investigações históricas sobre a formação e desenvolvimento das práticas sanitárias e de ensino (Nunes, 1993a). A análise crítica será marcada pela produção de alguns trabalhos que se tornaram referências obrigatórias: Donnangelo (1975, 1976) \& Arouca (1975).

Cumpre lembrar, como assinala Costa (1992), que: "Essas preocupaçōes teóricas ou de procedimentos foram condiçōes necessárias, porém não suficientes para explicar a enorme repercussão que o campo das ciências sociais teve na saúde coletiva". Salienta, com bastante propriedade, que a primeira conjuntura da pesquisa em saúde coletiva, de 1975 a 1978, teve como "fontes constitutivas" os Programas PESES (Programa de Estudos Sócio-Econômicos em Saúde), na Escola Nacional de Saúde Pública/FIOCRUZ e o Instituto de Medicina Social na Universidade do Estado do Rio de Janeiro. Mostra como foi o desenvolvimento do apoio institucional que, naquele momento, tornou-se possivel através do Programa de Saúde Coletiva no âmbito da FINEP (Financiadora de Estudos e Projetos).

Havia, portanto, nesse momento, um conjunto de condiçôes políticas e institucionais que favoreciam o encaminhamento da revisão do modo de produzir especialistas que contemplassem novas propostas, e que reestruturassem o campo da saúde pública. Até a década de 50, a pós-graduação era realizada nas Escolas de Saúde Pública (São Paulo e Rio de Janeiro), ou no exterior. Os programas de residência médica vinculados aos departamentos de medicina preventiva e social surgem por volta de 1962, época também em que ocorre o desenvolvimento da pós-graduação stricto sensu nas escolas de saúcle pública. Os cursos descentralizados e posteriormente regionalizados da Escola $\mathrm{Na}$ cional de Saúde Pública/FIOCRUZ datam de 1975, e têm como objetivo formar especialistas, num esquema de pós-graduação lato sensu (Nunes, 1993b).

Todos os esforços de formação de recursos humanos, que se prolongam pela década de 80 , como será refericlo adiante, têm como horizonte a presença de uma economia que em toda a América Latina apresentava um quadro recessivo, desde fins dos anos 70, o que se agudiza por volta de 1982. A evidência clessa crise pode ser constatada quando se verifica que, em relação à nutrição, somente $48 \%$ das crianças até 5 anos podiam ser classificadas como "normais"; que a esperança de vida era de menos de 64 anos para a América Latina e de menos de 60 para a América Central; que persistia um diferencial na mortalidade infantil quando analisada por estratos sócio-econômicos, e que havia uma 
tendência a uma menor redução deste nos períodos de crise; que se observava um aumento dos acidentes de trabalho, da prevalência das doenças infecciosas e de outras patologias. Simultaneamente, reduziam-se os gastos públicos, em particular o gasto social e, mais especialmente, os da saúde.

Neste contexto, os Ministros de Saúde das Américas formulam a proposta da Atenção Primária, cuja Declaração de Princípios seria aprovada em Alma-Ata, em 1978. Para o Brasil, em particular, uma década nos separava de um dos momentos mais relevantes na discussão de um projeto para a saúde - a realização da VIII Conferência Nacional de Saúde, em 1986, que problematizaria e redefiniria a saúde, considerando-a como o resultado das condiçòes de existência em uma sociedade determinada, como direito de todos e dever do Estado.

\section{Evolução Histórica dos Cursos de Saúde Coletiva}

Acompanhando a evolução histórica dos cursos de pós-graduação stricto sensu (mestrado e doutorado) que se incluem na ampla denominaçào de "saúde coletiva", verifica-se que é a partir dos anos 70 que estes se iniciam. Como foi dito acima, a expressão "saúde coletiva" não era utilizada no início dos anos 70. Tanto assim, que os dois cursos que se tornaram paradigmáticos nesta área, como resultado dos primeiros movimentos de renovação no campo da saúde pública, denominavam-se de "medicina social", aquele criado em 1974, no Rio de Janeiro, junto ao Instituto de Medicina Social da UERJ, e aquele criado em 1975, em Xochimilco, junto à Universidade Autônoma Metropolitana, do México. A idéia de "saúde coletiva" é tratada em dois momentos, no ano de 1978: no I Encontro Nacional de Pós-Graduação em Saúde Coletiva, realizado em Salvador, e na Reunião SubRegional de Saúde Pública da OPAS/ALAESP, realizada em Ribeirão Preto. Paim (1982), ao resgatar as origens dessa discussão, assinala que: "Esta designação (...) representou a ruptura com o modelo docente e de investigação conformado e controlado pela Fundação Rockefeller no âmbito de um desses cursos [no cla Bahial e a busca de um marco conceitual alternativo para o conjunto dos cursos". Referese à discussão em torno da criação de uma entidade que congregaria todos os cursos de pós-graduação dessa área. Em dezembro de 1978, quando da Reunião realizada em Ribeirão Preto, após a apresentação dos diversos programas, foi agendada uma reunião que teria como finalidade a criação de uma Associação de Pós-Graduação. Isto se efetivou em 27/9/1979, durante a realização da I Reunião sobre a Formação e Utilização de Pessoal de Nível Superior na área de Saúde Coletiva, promovida pelos Ministros da Saúde e Previdência e Assistência Social e pela OPAS, em Brasília. Criava-se a Associação Brasileira de Pós-Graduação em Saúde Coletiva ABRASCO, que tinha como objetivo a formação de pessoal em nível de pós-graduação. Esta formação deveria ser orientada por "um processo gerador de análise crítica do setor saúde na realidade social em que se insere; que seja potencialmente capaz de influir no campo da docência, pesquisa e prestação de serviços". O Documento Preliminar afirma em uma de suas partes que: "Em termos de conteúdo programático, a Associação reconhece que se deva estabelecer um adequado equilíbrio entre os conteúdos técnicos e teóricoconceituais, entre o 'biológico' e o 'social', entre o 'operacional' e o 'crítico', como forma de evitar o 'tecnicismo' e o 'biologismo' presentes na tradição de ensino da área de Saúde Coletiva" (ABRASCO, 1982).

Assim, em 1979, foi cunhado por um grupo de profissionais de saúde do Brasil o termo "Saúde Coletiva", ao mesmo tempo em que se criava uma Associação de moldes corporativos, agregando profissionais com formação em diferentes áreas do conhecimen- 
to. Esses profissionais eram oriundos das áreas de Saúde Pública e/ou Medicina Preventiva e Social e, como já foi observado, a ênfase recaía na orientação teórico-metodológica e política em relação à saúde, de modo a privilegiar o social como categoria analítica.

Atualmente, existem no Brasil quinze cursos em nível de Mestrado e oito em nível de Doutorado, aí incluidos os cursos denominados stricto sensu de Saúde Coletiva, Saúde Pública e Epidemiologia. A eles se agregam, no âmbito da pós-graduação em Saúde Coletiva, seis Mestrados e um Doutorado em Enfermagem; dois Mestrados e um Doutorado em Odontologia Social; um Doutorado em Engenharia Biomédica; um Doutorado em Demografia e um Mestrado em Administração Hospitalar e Serviços de Saúde.

Abaixo são discriminados os cursos incluídos na dimensão stricto sensu da Saúde Coletiva, de acordo com a sua denominação atual, local, nível, data de criação e áreas de concentração.

- Saúde Comunitária - Salvador - UFBa - Mestrado, criado em 1973 (curso multiprofissional); áreas de concentração: epidemiologia e administração e planejamento em saúde.

- Saúde Pública/Epidemiologia - Salvador - UFBa - Doutorado, credenciado em 1989 (para quem tenha o título de mestre em Saúde Coletiva).

- Saúde Pública - Rio de Janeiro - Escola Nacional de Saúde Pública - Mestrado, criado em 1977, com as seguintes áreas de concentração: Epidemiologia Geral, Epidemiologia das Grandes Endemias, Planejamento em Saúde, Saúde do Trabalhador, Saúde Ambiental, Saúde e Sociedades, Toxicologia Ocupacional (cursos multiprofissionais).

- Saúde Pública - Rio de Janeiro - Escola Nacional de Saúde Pública - Doutorado, criado em 1980 (curso multiprofissional), contando com as mesmas áreas de concentração do Mestrado.
- Saúde Coletiva - Rio de Janeiro - Instituto de Medicina Social/UERJ - Mestrado, criado em 1974 (curso multiprofissional), áreas de concentração: ciências humanas e saúde, epidemiologia e política, planejamento \& administração de serviços.

- Saúde Coletiva - Rio de Janeiro - Instituto de Medicina Social/UERJ - Doutorado, criado em 1991 (curso multiprofissional), contando com as mesmas áreas de concentração do Mestrado.

- Saúde Coletiva - Campinas - Faculdade de Ciências Médicas/UNICAMP — Mestrado (curso multiprofissional), criado em 1991. O curso anterior com a denominação de Mestrado em Medicina - área de concentração em Saúde Coletiva, criado em 1985, · somente para profissionais médicos, foi substituído pelo atual.

- Saúde Coletiva - Campinas - Faculdade de Ciências Médicas/UNICAMP - Doutorado (curso multiprofissional), criado em 1991. O curso anterior com a denominação de Doutorado - área de concentração em Saúde Coletiva, criado em 1985, somente para médicos, foi substituído pelo atual.

- Medicina Preventiva - Ribeirão Preto Faculdade de Medicina/USP - Mestrado (curso somente para médicos), criado em 1971.

- Medicina Preventiva - Ribeirão Preto - Faculdade de Medicina/USP - Doutorado (curso somente para médicos), criado em 1971.

- Medicina Preventiva - São Paulo - Faculdade de Medicina/USP - Mestrado (curso somente para médicos), criado em 1973.

- Medicina Preventiva - São Paulo - Faculdade de Medicina/USP - Doutorado (curso somente para médicos), criado em 1973,

- Saúde Pública - São Paulo - Faculdade de Saúde Pública/USP - Mestrado (curso multiprofissional), criado em 1970, áreas de concentração: Epidemiologia, Nutrição, Saúde Ambiental, Serviços de Saúde Pública, Administração Hospitalar, Saúde Materno-Infantil. 
- Saúde Pública - São Paulo - Faculdade de Saúde Pública/USP — Doutorado (curso multiprofissional), criado em 1970, contando com as mesmas áreas de concentração do mestrado.

- Saúde Coletiva - Londrina/Paraná Faculdade de Ciências da Saúde - Mestrado (curso multiprofissional), criado em 1990.

- Saúde Pública - Recife/Pernambuco FIOCRUZ/Centro de Pesquisas Ageu MagaIhães/Núcleo de Pesquisas em Saúde Coletiva - Mestrado (curso multiprofissional), criado em 1995, início das atividades em 1996, áreas de concentração: epidemiologia e planejamento e gestão de serviços.

- Saúde Coletiva - Campo Grande - Universidade Federal de Mato Grosso do Sul Mestrado (curso multiprofissional), instalado em 1992.

- Saúde Coletiva - Cuiabá - Instituto de Saúde Coletiva - Universidade Federal de Mato Grosso - Mestrado (curso multiprofissional), área de concentração saúde e ambiente, criado em 1993.

- Saúde Coletiva - Cuiabá - Instituto de Saúde Coletiva - Universidade Federal de Mato Grosso - Doutorado (curso multiprofissional), área de concentração: saúde e sociedades, criado em 1993.

- Epidemiologia - São Paulo - Escola Paulista de Medicina - Mestrado (curso multiprofissional), criado em 1988.

- Epidemiologia - Pelotas/Rio Grande do Sul - Faculdade de Ciências Médicas Mestrado, criado em 1990.

- Saúde Pública - Fortaleza/Ceará - Centro de Ciências da Saúde/Universidade Estadual do Ceará - Mestrado, área de concentração: Políticas e Serviços de Saúde, Nutrição em Saúde Pública, Saúde Mental em Saúde Pública. Criado em 1993, início das atividades em 1994.

- Saúde Pública/Epidemiologia - Fortaleza/Ceará - Universidade Federal do Ceará - Mestrado, criado em 1993, início das atividades em 1994.

- Saúde Pública/Epidemiologia - Belo
Horizonte/Minas Gerais - Universidade Federal de Minas Gerais - Mestrado, criado em 1992.

A reconstituição da história dos cursos de Saúde Coletiva no Brasil, evidencia que, a partir de 1980, houve uma crescente preocupação em definir o campo da Saúde Coletiva, já que esta questão, que poderia parecer secundária, reveste-se da maior importância. Isto porque não se trata simplesmente da denominação de um campo de trabalho, mas de saber quais são os seus conteúdos. Em 1981, Paim (1982) apontava, num tópico denominado "O objeto e a prática da Medicina Social", que: "A atual compreensão do objeto dessa disciplina sugere o envolvimento de questões no âmbito das ciências biológicas e sociais, exigindo, portanto, uma abordagem teórica e metodológica que utilize conhecimentos epistemológicos das duas áreas". No sentido de delimitar essas questões, incluía "o estudo dos determinantes da produção social das doenças e da organização social dos serviços de saúde, além da historicidade do saber e das práticas de saúde".

Como foi apontado acima, esta questão iria se tornar recorrente com o passar do tempo. Não se pode deixar de mencionar que, em seus inícios, foi ela objeto de um texto que se tornaria referência obrigatória no trato deste assunto. Preparado por Cecília Donnangelo, para o II Encontro Nacional de Mestrados e Doutorados na área de Saúde Coletiva, realizado em 1982, baseava-se em um trabalho escrito em colaboração com Oswaldo Campos e apresentado em dezembro de 1981 no Seminário sobre Saúde Pública, organizado pela FUNDAP/SP (Donnangelo, 1983). Trata-se da revisão feita pela autora sobre as principais tendências da produção científica na área da Saúde Coletiva nos anos 70. Como escreve Donnangelo, ao discutir a questão da produção procurava estabelecer "uma delimitação aproximada do campo, não através de definiçōes formais e sem referência 
à especificidade que adquire, na sociedade brasileira, determinado conjunto de práticas relacionadas à questão da saúde". Afirma a autora que para se chegar a entender o campo da Saúde Coletiva é necessário contrapôlo às práticas da medicina individual. Quanto a esta última, sua institucionalizaçào assentava-se em uma estrutura de saber e prática que tinha como centro o indivícluo e o biológico, e, mais do que isso, havia "permanecido relativamente resguardada dos efeitos de reordenaçōes econômicas e político-ideológicas". Prossegue, lembrando que essa estrutura era relativamente estável e unívoca. O mesmo não acontece com a Saúde Coletiva. Escreve Donnangelo (1983): "As práticas designadas de 'saúde coletiva', propostas originalmente como campo da Saúde Pública institucionalizada, não partilham dessa homogeneidade do saber médico. A imprecisa designação de Coletivo tem recoberto efetivamente distintos objetos de saber e de intervenção". Salienta o fato de que a noção de coletivo tem sido freqüentemente utilizada de maneira acrítica para designar um campo supostamente uniforme. Na época em que escreveu, e frente à produçâo existente, verificou que havia "marcadas variações temáticas, pela ênfase em distintos objetos e em distintos campos de saber, por variações temáticas e metodológicas de análise, por distintas opções sobre modelos experimentais". Resumia a situação, afirmando: "Essas variações reproduzem, efetivamente, a amplitude possivel da gama de conotações assumidas pela noção de coletivo: coletivo/meio; coletivo/conjunto de indivíduos; coletivo/interação entre elementos; coletivo como conjunto de efeitos ou conseqüências da vida social; coletivo transformado em social como campo específico e estruturado de práticas". Ressalte-se que o ponto fundamental nessa concepção, mesmo heterogênea, de coletivo, é a necessidade de que este seja sempre tomado em suas manifestações histórico-concretas.

Posteriormente, Fleury (1985) retomaria os pontos centrais acima delineados, incor- porando, à compreensão do objeto da saúde coletiva, as idéias desenvolvidas por Pereira (1983). Para este autor, a Medicina Social trataria dos aspectos sociais e institucionais da medicina, no sentido de compreender os processos que mantêm a saúde ou provocam a doença e para as práticas sociais que procuram recuperar ou manter aquela. Textualmente, afirma: "Trata-se de uma mudança qualitativa, porque o objeto de tal disciplina não seria representado por corpos biológicos, mas por corpos sociais. Não se trataria, tão-somente, de indivíduos, mas de sujeitos sociais, de grupos e classes sociais e de relações sociais referidas ao processo saúde-doença. Deste ponto de vista as práticas sociais da medicina seriam objeto, especificamente, dessa disciplina de fronteira". Aponta como grande desafio para o campo o fato da adoção de um objeto ao mesmo tempo natural e histórico-social.

Paulatinamente, o campo da Saúde Coletiva desenvolveu uma série de investigaçōes, o que proporcionou à área uma conformação. Assim, a Saúde Coletiva toma como seu objeto a própria análise das formaçôes discursivas, como se constróem conceitos e objetos, mas ao mesmo tempo se depara com a problemática de repensar a determinação da doença, não mais no modelo da epidemiologia clássica, mas dentro de um paradigma que privilegie o social. Some-se a isso a necessidade de desvendar a própria organização social da prática médica, na medida em que esta se estrutura através de relações políticas, econômicas e ideológicas, quer na expressão dos serviços de saúde, ou nas propostas das políticas de saúde. Hoje, no momento em que se revisam muitas das formulações que originariamente embasaram a compreensão das políticas sociais, objeto do "desvio determinista" - leia-se, economicista - é importante não cair em outra forma de reducionismo. Este aspecto foi enfatizado por Oliveira (1992), ao tecer uma série de comentários no Seminário sobre "Saúde e Políticas Sociais na América Latina", ao lembrar a impor- 
tância de estabelecer a relação entre estruturas e processos, estrutura e atores, a fim de evitar a simples desqualificação do elemento da determinação, sem que nada seja posto em seu lugar.

De um modo geral, estes aspectos têm permeado os cursos de pós-graduação, ou seja, estes têm procurado compreender a doença como fenômeno social e a prática em saúde como uma prática social. Assim, alguns cursos, como o da Bahia, explicitam estes pontos quando assinalam que o modelo curricular toma como pressupostos que "A saúde, enquanto estado vital, setor de produção e campo de saber, está articulada à estrutura da sociedades através das suas instâncias econômicas e político-ideológicas"; que "As ações de saúde (promoção, proteção, recuperação, reabilitação) constituem uma prática social e trazem consigo as influências do relacionamento dos grupos sociais". Afirma-se que "O objetivo da Saúde Coletiva está constituído nos limites do biológico e do social e compreende a investigação dos determinantes da produção social das doenças e da organização social dos serviços de saúde e o estudo da historicidade do saber e das práticas sobre os mesmos" (ABRASCO, 1982).

De forma menos detalhada, o Curso do Instituto de Medicina Social da UERJ formula também esta perspectiva, quando define que os objetivos do curso são: "Formar mestres em Saúde Coletiva capacitados a desenvolver pesquisa, ensino e prestação de serviços no campo da Saúde Coletiva; desenvolver instrumentos de reflexão sobre a medicina como prática social, analisando a gênese e o desenvolvimento do saber e das práticas de saúde, bem como suas dimensões técnicas, econômicas e político-ideológicas" (ABRASCO, 1982).

De outro lado, embora sem assumir uma definição explícita de Saúde Coletiva, outros cursos procuram compor um elenco de disciplinas que possam dar conta dessas dimensões, como, por exemplo, o curso ministrado na UNICAMP, ou o de Londrina, entre outros.
O que se percebe é que, embora exista um núcleo comum (em geral formado pelas disciplinas de Epidemiologia e Ciências Sociais), há uma grande diversidade de áreas e temas compondo o quadro atual dos cursos de pós-graduação. Esta dimensão é mais evidente nos cursos ministrados nas Escolas de Saúde Pública, embora os cursos criados em épocas mais recentes já enfrentem hoje este problema. Lembremos que a questão do conteúdo foi um dos principais pontos discuticlos na Oficina de Avaliação da Pós-Graduaçào stricto sensu em Saúde Coletiva, realizada em Porto Alegre, em 16-17/5/92. Nessa Oficina, os participantes constataram que, dada a natureza interdisciplinar complexa e abrangente do objeto da Saúde Coletiva, há necessidade de se repensar a própria estrutura dos cursos. Ou seja, essa pós-graduação deve ter um caráter especializado, tendência que já vem se observando de maneira bastante expressiva. Como está no documento desse grupo, "há uma tendência à formação de áreas de concentração no interior dos cursos já existentes e da abertura de novos cursos com organização curricular em torno de grandes áreas temáticas como Epidemiologia, Planejamento, Administração em Saúde, Saúde Ambiental, etc." (Minayo, 1992a).

Em certo sentido, esta questão se torna mais patente nos cursos que têm lugar nas Escolas de Saúde Pública que, pela própria estrutura e propósitos, compreendem uma extensa variedade de conteúdos. Em recente discussão na Escola Nacional de Saúde Pública, Minayo (1992b) afirmava que um dos problemas a ser enfrentado é o "de que não existe consenso na área em que lidamos, dada a sua complexidade, polissemia e fragilidade no estabelecimento de paradigmas". Para tal, impunha-se dar uma resposta à questão: Existe um núcleo comum de conteúdo indispensável à pós-graduação em Saúde Pública ? Se existe, qual ? Especificamente, como ela deveria ser tratada em nível de Mestrado e Doutorado? Previamente, foram entrevistados vin- 
te e sete professores, dos quais vinte e quatro $(88,9 \%)$ optaram, basicamente, pela idéia de currículos diversificados, segundo as diferentes temáticas; apenas três $(11,1 \%)$ optaram por algo próximo da proposta de um currículo "igual para todos". Entre os que fizeram a primeira opção, dois sugeriram a inclusão de uma disciplina comum obrigatória (Histórico e Conceituação da Saúde Pública) e um sugeriu outras disciplinas, além da citada acima: Epidemiologia, Introdução aos Métodos Quantitativos e Sistemas de Saúde (Oliveira, s.d.).

Em realidade, a Escola Nacional de Saúde Pública ministrou, a partir do primeiro semestre de 1992, a disciplina "História e Paradigmas do Pensamento e da Prática Social em Saúde" para todos os pós-graduandos em nível de Mestrado e recomendada ao Doutorado (Nunes, 1992). Esse curso foi dividido em três unidades que trataram dos seguintes aspectos:

Unidade I - Os saberes, a ciência e os paradigmas;

Unidade II - A constituição do campo da saúde coletiva - trajetória;

Unidade III - A constituição do campo da saúde coletiva: disciplinas e temas;

Unidade IV - Conhecimento e prática em saúde coletiva: um desafio permanente.

Esta última aspecto foi objeto de uma mesa-redonda, visando sistematizar três pontos: a prática teórica, a prática política e a prática pedagógica - considerados fundamentais na concepção da saúde coletiva.

Já se teve oportunidade de mencionar que tanto na Escola Nacional de Saúde Pública, como na Faculdade de Saúde Pública há diversas sub-áreas de concentração. O que se pode constatar é que o perfil desses cursos difere daqueles que se desenvolvem no interior dos Departamentos de Medicina Preventiva e Social. Não se trata de rever todos os conteúdos desses cursos, mas apontar que existe uma grande heterogeneidade, embora, como já foi afirmado, haja um certo núcleo comum. De certa forma, essas estruturas curriculares prendem-se às próprias origens dos cursos e também a uma tradição em torno de determinados objetos de investigação. Citese, por exemplo, a intensa e extensa investigação epidemiológica realizada na pós-graduação de Ribeirão Preto, desde o início de suas atividades, em 1971. Isto não impediu que se associasse à pesquisa de caráter epidemiológico a análise de problemas relacionados à assistência médica e mesmo à educação médica. Trabalho escrito por Rocha, Nogueira, Pereira \& Simões (1978) reportava-se aos diversos enfoques que orientaram as pesquisas - epidemiológico-preventivista, da medicina comunitária, da teoria dos sistemas e histórico-estrutural - fornecendo um quadro geral da situação e explicitando as vinculações dos conteúdos do programa de pós-graduação e das pesquisas realizadas.

Quanto aos programas de criação mais recente, como no caso da UNICAMP, percebe-se que se está em busca da melhor adequação de conteúdos, a fim de abranger uma formação teórica mínima em Saúde Coletiva. Dessa forma, as disciplinas obrigatórias irão tratar da metodologia epidemiológica, bioestatística, elementos teóricos de saúde coletiva e métodos de investigação em saúde coletiva. Há disciplinas opcionais e geralmente incentiva-se, de acordo com os temas de pesquisa escolhidos e frente à necessidade de aprimoramento em determinados aspectos, que sejam feitos cursos em outras unidades e departamentos da Universidade, ou mesmo em outras instituições.

\section{Considerações Finais}

O que se pode perceber claramente é que, durante as duas décadas que nos separam da criação dos primeiros cursos em Saúde Coletiva, a área conseguiu, em um tempo relativamente curto, estabelecer um bem-sucedido processo de institucionalização. Há, sem dú- 
vida, um amplo caminho a percorrer, mas já existe um quadro de realizações que permite avaliá-lo como altamente positivo. Esta apresentação tratou exclusivamente da pós-graduação stricto sensu; e, em relação a esse processo, uma questão a ser ressaltada é a presença da especialização, com a conseqüente tendência à formação de áreas de concentração. De outro lado, chama a atenção o fato de que a demanda atual de caráter multiprofissional conduz, necessariamente, à criação de um núcleo comum para os cursos onde já existem tradicionalmente áreas de concentração e, nos cursos onde não existem essas áreas, o fortalecimento de disciplinas básicas de caráter geral. Nessa direção, a existência de disciplinas sobre metodologia científica e filosofia da ciência são de fundamental importância, não devendo nos esquecer que a presença das ciências humanas tem balizado o campo da saúde coletiva. Birman (1991), na apresentação de Physis - Revista de Salide Coletiva, enfatizava que "a constituição do discurso teórico da saúde coletiva, com a introdução das ciências humanas no campo da saúde, reestrutura as coordenadas desse campo, destacando as dimensões simbólica, ética e política, de forma a revitalizar o discurso biológico". A mesma proposta aparece também no Editorial da Revista Saúde e Sociedade (1992), ao destacar o caráter multidisciplinar da Saúde Coletiva e a necessidade de abrir "maior espaço para as áreas das ciências humanas cuja contribuição ao campo da Saúde Coletiva apresenta-se como primordial".

Ainda, como lembra Birmam (1991), é importante que o campo teórico da saúde coletiva promova "uma leitura diferenciada das relações estabelecidas entre natureza e sociedade por outros saberes, já que, quando isolado, o discurso naturalista encontra limites para realizar este trabalho". Tornar-se-ia repetitivo insistir que, por ser uma área profundamente marcada pela diversidade e historicidade dos objetos com que trabalha, a saúde coletiva vê-se, continuamente, às voltas com a dificul- dade de delimitar de forma clara e acabada o seu âmbito de práticas e saberes. Gonçalves (1991), destacava que, entre outras ocorrências na década de 80 , haviam surgido outros recortes da realidade que não tomavam a doença como parâmetro. Estão entre estes a "saúde da mulher", a "saúde do trabalhador", a "saúde do deficiente", a "saúde mental" e, acrescente-se, o mais recente, a "saúde ambiental". Para o autor, a constituição dessas reflexões e práticas foi decorrência da participação ativa de muitos grupos da sociedade, da atitude crítica, da interação militante e da multidimensionalidade de enfoques.

Possivelmente, as características dos cursos de pós-graduação destacadas neste trabalho impedem, até certo ponto, que se proponha um modelo único para a sua organização. Assim, ao assumirmos a necessidade de diversificação interna, provavelmente concorremos para uma maior efetividade da "especialização" dessa área, a qual, a partir de uma perspectiva geral, poderia estabelecer, na expressão de Foucault (1972), os seus "discursos parcelares". Ao demarcar e analisar as "formaçōes discursivas" inerentes a cada campo, poder-se-ia nesse grupo de enunciados "demarcar e definir um referencial, um tipo de desvio enunciativo, uma rede teórica, um campo de possibilidades estratégicas".

Isto, com toda certeza, não invalida o que tem sido discutido e exposto pelos especialistas, mas reforça a posição que afirma, como Frenk (1992), que: "A saúde é um ponto de encontro. Aí confluem o biológico e o social, o indivíduo e a comunidade, a política social e a econômica. Além de seu valor intrínseco, a saúde é um meio para a realização pessoal e coletiva. Constitui, portanto, um índice do êxito alcançado pela sociedade e suas instituiçōes de governo na busca do bem-estar que, no fim das contas, é o sentido último do desenvolvimento".

Para isso, deve-se estar atento à formação de recursos humanos que possam estabelecer uma reflexão crítica contínua acerca da realidade de saúde, com base em um crescen- 
te aprofundamento conceitual e teórico, a fim de que a identificação clara e objetiva dos problemas possa redundar na formulação de políticas de saúde de cunho democrático e transformador. Esta seria, sem dúvida, uma forma de enfrentar os inúmeros problemas

\section{Referências bibliográficas}

ABRASCO (1982) - Ensino da Saúde Pública, Medicina Preventiva e Social no Brasil. Relatório Final, pp. 77-92, 110-117.

ABRASCO (1983) - Ensino da Saúde Pública, Medicina Preventiva e Social no Brasil. II Encontro Nacional de Mestrados e Doutorados na área de Saúde Coletiva - Relatório Final 2:137-143.

ABRASCO (1986) - Estudos de Saúde Coletiva. Reunião de Avaliação do Programa de Saúde Coletiva FINEP/CNPq - Relatório Final 4:69-89.

ABRASCO (1988) - Estudos de Saúde Coletiva. Encontro Nacional de Pós-Graduação em Saúde Coletiva e Reforma Sanitária - Relatório do Grupo de Mestrados e Doutorados 5:125-126.

AROUCA, A. S. da S. (1975) - O dilema preventivista: contribuição para a compreensão e crítica da Medicina Preventiva. Tese de Doutorado. Campinas: Faculdade de Ciências Médicas, UNICAMP, mimeo.

BIRMAN, J. (1991) - A physis da Saúde Coletiva. Physis - Revista de Sañde Coletiva 1(1):7-11.

CANDEIAS, N. M. F. (1984) - Memória histórica da Faculdade de Saúde Pública da Universidade de São Paulo. Revista de Sañde Píblica 18:2-60.

COSTA, N. do R. (1992) - Política e projeto acadêmico: notas sobre a gênese da Saúde Coletiva. Cadernos de História e Sande 2:125-136.

DONNANGELO, M. C. F. (1975) - Medicina e sociedade. São Paulo: Pioneira sanitários, procurando conciliar ao saber acadêmico o saber militante, tão bem explicitado por Max Weber em 1918, em duas conferências magistrais e fontes de sabedoria sociológica: "A Ciência como Vocação" e "A Política como Vocação" (Weber, s.d.).

DONNANGELO, M. C. F. \& PEREIRA, L. (1976) - Saúde e sociedade. São Paulo: Duas Cidades.

DONNANGELlO, M. C. F. (1983) - A pesquisa na área de Saúde Coletiva no Brasil a clécada de 70. In: ABRASCO - Ensino de Salide Paiblica, Medicina Preventiva e Social no Brasil 2:19-35.

FLEURY, S. M. (1985) - As Ciências Sociais em Saúde no Brasil. In: Nunes, E.D. (org.) - As Ciências Sociais em Saúde na América Latina: tendências e perspectivas. Brasília: Organização Pan Americana da Saúde.

FOUCAULT, M. (1972) - A arqueologia do saber. Petrópolis: Vozes.

FOUCAULT, M. (1979) - O nascimento da Medicina Social. In: Machado, R. (org.) Microfisica do poder. Rio de Janeiro: Graal.

FRANCO, S. \& NUNES, E. D. (1991) Presentación. In: Franco, S., Nunes, E. D., Breilh, J. \& Laurell, A. C. (orgs.) - Debates en Medicina Social. Quito: Organización Panamericana de la Salud.

FRENK, J. (1992) - La nueva Salud Pública. In: La crisis de la Salud Püblica - reflexiones para el debate. Washington: Organización Pan Americana de la Salud.

GARCÍA, J. C. (1972) - La educación médica en América Latina. Washington: Organización Panamericana de la Salud.

GONÇALVES, R. B. M. (1991) - A saúde no Brasil: algumas características do processo histórico nos anos 80. São Paulo em Perspectiva 5:99-106

GUÉRIN, J. (1848) - Médicine Sociale. Au 
corps médicale de France. Gazette Médicale de Paris mars 11.

MINAYO, M. C. de S. (1992a) - Oficina de Avaliação da Pós-Graduação stricto sensu em Saúde Coletiva, Porto Alegre, 16-17/5/1992, mimeo.

MINAYO, M. C. de S. (1992b) - Notas para reflexo sobre a Pós-Graduação stricto sensu na ENSP/Fiocruz, Rio de Janeiro, mimeo.

NUNES, E. D. (1992) - Programa do Curso História e Paradigmas do Pensamento Social em Saúde. Escola Nacional de Saúde Pública/FIOCRUZ, Rio de Janeiro, mimeo.

NUNES, E. D. (1993a) - Notas para a história das Ciências Sociais em Saúde na América Latina. Revista del Instituto Juan César Garcia 3:48-55.

NUNES, E. D. (1993b) - A formação de sanitaristas no Brasil com especial referência aos Cursos Descentralizados de Saúde Pública. Municipio e Saíde 1:46-53.

NUNES, E. D. (1994) - Sobre a História da Saúde Pública: revisando alguns estudos. Apresentado no I Encuentro Iberoamericano de Historiadores en Salud Pública, Havana (Cuba), 14-18/2/94, mimeo.

OLIVEIRA, J. A. (s.d.) - Consolidação das respostas ao questionário enviado pela Comissão de Pós-Graduação/Escola Nacional de Saúde Pública/FIOCRUZ, mimeo.

OLIVEIRA, J. A. (1992) - Considerações sobre o Seminário "Salud y Políticas Sociales en América Latina". In: Teixeira, S.F. (org.) Estado y políticas sociales en América Latina. México: UAM.
ORGANIZACIÓN PANAMERICANA DE LA SALUD (1992) - La crisis de la Salud Pública: reflexiones para el debate. Publicación Cientifica n. 540. Washington: OPS

PAIM, J.S. (1982) - Desenvolvimento teórico-conceitual do ensino em saúde coletiva. ABRASCO, Rio de Janeiro, mimeo.

PAIM, J.S. (1991) - La salud colectiva y los desafios de la práctica. In: La Crisis de la Salud Pública - reflexiones para el debate. Publicación Cientifica n. 540. Washington: OPS.

PEREIRA, J.C.M. (1983) - A explicação sociológica na Medicina Social. Tese de LivreDocência, Ribeirão Preto, Faculdade de Medicina, Universidade de São Paulo.

ROCHA, J.S.Y.; NOGUEIRA, J.L.; PEREIRA, J.C. de M. \& SIMES, B.J.G. (1978) - Pesquisa aplicada a serviços de saúde: Experiência do Departamento de Medicina Social da Faculdade de Medicina de Ribeirão Preto da USP, Ribeirão Preto, mimeo.

ROSEN, G. (1983) - A evolução da Medicina Social. In: Nunes, E.D. (org.) - Medicina social: aspectos históricos e teóricos. São Paulo: Global.

SAÚDE \& SOCIEDADE (1992) - Editorial. 1:1-2.

SCHRAMM, R. F. (1993) - A terceira margem da saúde: a ética natural. Complexidade, crise e responsabilidade no saber-fazer sanitário. Tese de Doutorado. Rio de Janeiro: Escola Nacional de Saúde Pública/FIOCRUZ.

WEBER, M. (s.d.) - Ensaios de Sociologia. Rio de Janeiro: Zahar Editores. 